\title{
Get Involved: K.N. Subramanian-Organizer, Collaborator, Mentor
}

\section{Maria Guzzo}

"Get Involved" is a recurring End Notes feature that spotlights the work of TMS volunteers and

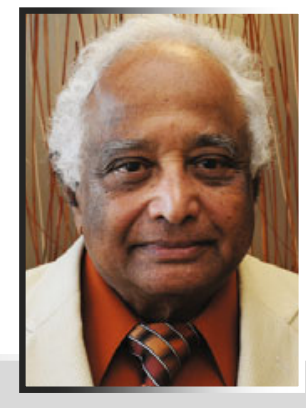
shows the wide range of activities available through TMS. This month, K.N. Subramanian, professor in the Department of Chemical and Materials Science at Michigan State University, discusses his participation in TMS for more than 50 years, and his recent receipt of the Electronic, Magnetic, \& Photonic Materials Division (EMPMD) Distinguished Scientist/Engineer award.

Q. You have been very active in the Electronic, Magnetic, \& Photonic Materials Division (EMPMD) over the last 16 years. Could you briefly describe your involvement, what made it the most memorable and why?

A. I have been attending TMS meetings for over 50 years. However, my first experience in the symposia sponsored by EMPMD on electronic interconnects about 16 years ago was the most inspiring. I was amazed at the collaborative effort of international researchers, from industry, national laboratories and universities to find suitable lead-free electronic solders as alternatives to traditional leaded solders used in electronics. I have never realized such comradely cooperation among researchers. Since then, I have devoted most of my research efforts to the area of lead-free electronic solders, and have maintained very active research groups that have produced several leading researchers, who are independently pursuing advancements in this area.

Q. Has that experience helped you to become more involved in TMS? How?

A. Prior to this experience, my involvement in TMS was participating in various committees and organizing symposia. I was also involved with several technical societies, but the emphasis of these activities depended on my research focus at any given time. However, since my involvement in lead-free electronic solders 17 years ago and my involvement in EMPMD activities 16 years ago, my research focus has not changed. This concentrated, continuous involvement in a very challenging field has developed significant contacts with internationally recognized researchers. We meet regularly during TMS meetings. Based on the relationships I have built, I have been invited to and have edited two books. Chapters in these books are invited contributions from leading researchers addressing the specific area of their expertise. These leading authors are regular attendees of TMS symposia.

Q.What current opportunties are available in EMPMD and how can other TMS members get involved in these initiatives?

A. Members, in addition to presenting papers, should join appropriate committees and organize symposia. Initially, it should be in collaboration with senior members. Such mentoring will guide the young member toward a successful and productive future, and help them gain experience and develop contacts. In addition to attending technical sessions, members should also attend social functions, such as the student-faculty mixer. In addition, each technical committee has representatives in several organizational activities of TMS. The Membership and Student Development Committee and Program Committee are typical examples. Getting involved in such activities can broaden the technical and organizational experience of the members.

Q. In reflecting on your long association with TMS, what aspects of volunteering would you recommend to our young professionals and to our more tenured professionals?

A. Get involved. Collaborate. Mentoring young members during their early experience in committees is an important role senior members should take. Similarly, young professionals should reach out to those who have been successful in their career. This way we will develop continuity in our activities. In addition, it is important to be focused, instead of trying to be jack of all trades, but master of none.

Maria Guzzo is a contributing writer for JOM. 